\title{
Can Academic Success Come from Five Minutes of Physical Activity?
}

\author{
Julienne K. Maeda \\ University of Hawaii \\ Lynn M. Randall \\ University of New Brunswick
}

\begin{abstract}
Being physically active helps not only in the areas of health and fitness, but also in the area of academics, more specifically, mathematics. Brain-based teaching can play a large role in enhancing student learning through the use of movement, in particular, a short running activity on math fluency in addition problems. Could five minutes of a moderate to vigorous activity have any effect on students' addition fluency? The purpose of this article is to share with readers the effects of infusing a short physical activity into an already busy day. Two primary findings were gleaned from this study. First, although there was a small positive effect on math fluency, there was no negative effect. Second, positive changes in students' behavior were noted by the classroom teacher.
\end{abstract}

\section{Introduction}

After as little as five minutes of a moderate-vigorous physical activity (i.e., running) four days a week, a class of second grade children was able to concentrate more, the teacher was able to complete more activities, math fluency increased, and the daily classroom routines and overall grades of the students were not negatively affected by the running; rather both improved as a result. The purpose of this article is to share with readers the ingredients for infusing a short physical activity into a busy day.

Julienne K. Maeda is an Assistant Professor at the University of Hawaii at Manoa in Honolulu. Lynn M. Randall is an Assistant Professor at the University of New Brunswick in Fredericton. Both have research interests in aspects of elementary physical education, one of which is the balance between physical activity and academic performance. 
Physical inactivity and unhealthy eating contribute to at least 300,000 preventable deaths each year (US Department of Health and Human Services, 2001). Becoming physically active on a regular basis is the key, and the activity need only be moderate in nature to reap benefits. Although regular participation in 30 minutes of intense activities or shorter more vigorous bouts of 15 minutes is suggested per exercise session for adults, such recommendations are different for children. Corbin and Pangrazi (1998) suggested that children accumulate at least 30-60 minutes of age and developmentally appropriate physical activities on all or most days of the week.

Schools provide an ideal place to help improve and develop more healthy habits (DHHS, 2001). Werner, Timms, and Almond (1996) reported that panelists from a news briefing by the American College of Sports Medicine suggested that "schools are the most likely place to change physical activity patterns and that physical education curricula should provide movement experiences that are enjoyable, provide significant amounts of physical activity, and promote lifelong participation in physical activity" (p. 49). Recesses and the time before and after school provide a small portion of time when children can be active. Regular participation in a developmentally appropriate physical education program is another portion of time for physical activity.

Elementary physical education is often children's first formal experience with movement instruction and it is a time where they begin building a foundation of motor skills for later participation in sports and other physical activities. Physically educated students learn the importance of being active, how to be active, and value such a lifestyle (National Association for Sport and Physical Education, 1995). They are students who become knowledgeable physical activity participants and spectators, practice the meaning of teamwork, and are provided the tools to become active, healthy adults. Although participation in physical education is a good source of physical activity and the breadth of benefits extends beyond the physical, it is often not allotted enough time with regard to the development and maintenance of fitness and motor skills. Elementary physical education programs taught by a physical education specialist in many parts of the United States and Canada are typically scheduled once a week per class, or even less as they are in several schools in Hawaii (i.e., once every two weeks). Supplemental days of physical education and/or shorter bouts of physical activity are important and would benefit students.

Historically, physical education has been viewed as a class that reduces instruction time in other content areas. Yet, numerous links have been made between the mind and body (Jensen, 1998) showing how efforts coordinating both can be much more effective. More recently, Sallis, McKenzie, Kolody, Lewis, Marshall, and Rosengard (1999) reported that physical activity levels 
found in elementary physical education classes taught by a specialist may in fact contribute to academic achievement. Spending more time in physical education did not have negative effects on standardized academic achievement test scores in the elementary school children in that study and the thinking that physical activity negatively affects cognitive function is untrue (Sallis et al., 1999).

\section{Movement \& Academics}

"Movement is an indispensable part of learning and thinking" (Summerford, 2001, p. 7). Furthermore, movement can help to reinforce the academic skills of all students (Blaydes, 2001; Jensen, 1998; Sallis, et. al., 1999). Although physical activity and movement do not necessarily make children smarter, they do contribute to how they learn and how much can be learned. According to Hannaford (1995), 85\% of children in school are kinesthetic learners. In other words, these children learn better by moving and interacting with their environment rather than sitting and only receiving information visually or by listening. The belief that movement should only be limited to physical activity in physical education is contrary to what is known as brain-compatible learning. In fact, with the outdated thinking that physical education is a frill, many students are missing the neural benefit movement can have on academics (Summerford, 2001). According to Jensen (2000, 1998), movement and physical education do, in fact, contribute to enhanced brain function.

However, with the increasing pressure and accountability in subject areas such as math and reading, time has become an even more precious commodity. Indeed, although time has become very valuable to teachers, planning as little as five minutes a day of concentrated physical activity could contribute to academic performance and student behavior. The purpose of this article is to share with readers a recipe for infusing physical activity into a busy day. After as little as five minutes of moderate-vigorous activity (i.e., running, walking), the children who participated in this study were able to concentrate more, the teacher reported being able to get more done, math fluency increased, and that fluency was not negatively affected by the physical activity.

\section{Methods \& Procedures}

\section{Participants}

The participants in this study were one second-grade class in an elementary school $(\mathrm{N}=19)$ in Hawaii. There were 7 boys and 12 girls who participated. Of the 19 students, 2 received special education services. 


\section{Procedures}

The teacher of the class divided the students into two groups based on their performance in math related to addition concepts, a) grade level group and b) below grade level group. Three versions (e.g., three sheets per version) of addition problem sheets were used. Three different versions were used to minimize any chance of students memorizing the problems and answers. Each version was used alternately throughout the week. For example, version 1 was used on day 1 , version 2 on day 2, version 3 on day 3 , then back to version 1 on day 4 , etc. Using dry-erase pens and transparency sheets, each student answered as many math problems as they could within one minute upon returning to the classroom after the walk and/or run. The teacher corrected all sheets then cleaned the transparencies.

A timer was used to signal the end of one minute. The use of oneminute timings is a short yet sufficient interval for measuring performance (Binder, Haughton, \& Van Eyk, 1990). The one-minute timings allow teachers and students to easily calculate per minute frequencies and accommodate those who have attention difficulties. Also, such a short period allows for many opportunities for students to respond and improve on fluency and for teachers to make curriculum-based decisions.

Fluency is a factor related to student learning. According to Binder et al. (1990), students must develop certain minimum levels of speed and accuracy on individual curriculum tasks. Fluency in this sense is defined as accurate, non-hesitant performance where work becomes steady for significant durations. Through short timings, where correct responses per minute are recorded, the number of opportunities to respond is high, thus helping to increase and improve fluency.

The weekly routine, approximately an hour after lunch four days a week, consisted of: restroom/water, physical activity, water, and then return to the classroom for the math activity. The walking/running route was near the classroom building or a short distance away (if it rained), and students ran and/ or walked the length of their building (i.e., a building that houses about 10 classrooms) for a period of five minutes. The classroom teacher had used this form of physical activity with previous years' classes and had introduced it to the participants in this study. Since the class was familiar with the route used, they did not need to be familiarized with it for this project. The teacher instructed them on what direction to take (e.g., clockwise direction) then sent them off for the five-minute time. Passing was only allowed after the first lap. On rainy days, the class walked/ran on a good stretch of walkway a short distance from their building. The teacher encouraged all of the children to keep moving throughout the five minutes. 


\section{Design}

Using a multiple treatment reversal design (Cooper, Heron, \& Heward, 1987), several phases depending on the intervention are provided. With this design, each phase served as a baseline for the subsequent phase (Cooper et al., 1987). Therefore, when experimental (i.e., intervention) variables are introduced, their effect is compared to the level of the baseline (i.e., Phase A) and when removed (i.e., subsequent phases other than A), the attempt is to reproduce baseline levels. It is the change in the trend of the data that is being examined via visual analysis through the use of graphs.

\section{Data Analysis}

In single-subject research, data are analyzed using visual analysis of graphs (Cooper et al., 1987). Visual analysis provides the viewer with their own means of interpreting the data and of judging any significance in behavior changes. In this study, Phase A (refer to Figure 1) otherwise known as the baseline, was composed of the one-minute timing of addition problems and no physical activity. A decreasing trend and data path are visible in all three Figures during Phase A. In other words, the number of correct problems per minute decreased during this phase.

Figure 1 - Class Medians

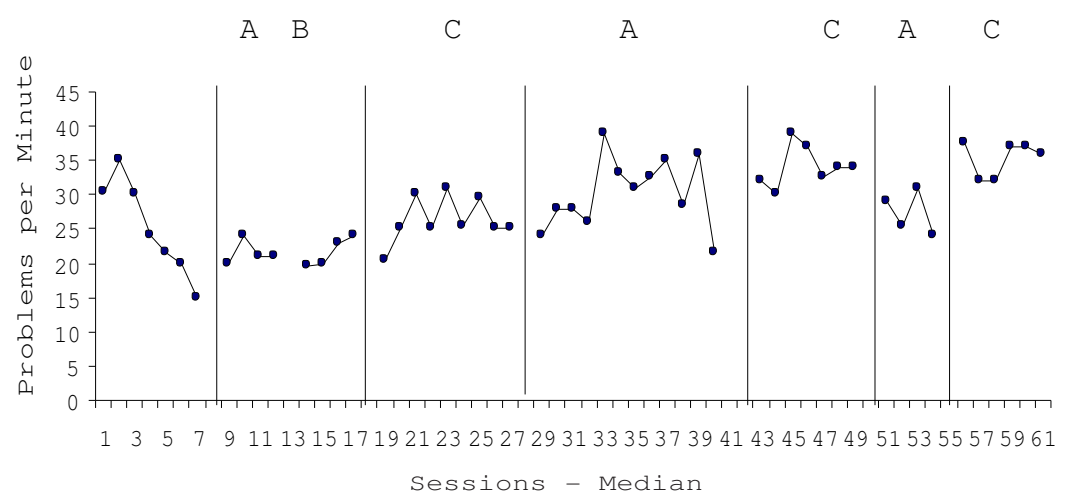

Phase B was the introduction of a physical activity (i.e., running) with the oneminute timing of addition problems immediately afterwards. The teacher reported that the students spent more of the five minutes walking than running. This could be explained by the low fitness level of the students. This study started approximately a little more than one month into a new school year, and in general, students do not tend to be in good physical shape after summer 
vacation. During this phase, the data path was slightly higher and much more stable than in the previous phase. However, since the majority of the students were walking for the five minutes instead of running, it was decided by the researchers to use walking as the next physical activity, hence Phase $\mathrm{C}$. The design of this study allows for changes to be made while the study is taking place to help improve the targeted behavior; any changes become a new phase (Cooper et al., 1987).

In Phase $\mathrm{C}$, students were encouraged to walk briskly for the fiveminute time period. In this phase, the data path increased and the number of addition problems answered correctly by the class increased. Once the data path in Phase $\mathrm{C}$ reach a point of relative stability, Phase A was re-introduced to see if a decrease in performance occurred as a result of no physical activity. In this second Phase A, math fluency seemed to continue at the level of the previous phase. However, after four sessions and a sharp increase in math problems answered correctly, performance again began to decrease. The sharp increase cannot be explained. With Phase $\mathrm{C}$ showing a positive effect when compared to Phase $\mathrm{A}$, Phase $\mathrm{C}$ was introduced again. With the re-introduction of Phase C, the data path returned to a higher level of fluency than Phase A and remained at a relatively high level. To attempt to repeat a return to baseline levels of performance, Phase A was again re-introduced. According to Cooper et al. (1987), a return to baseline levels again strengthens the design and effect of the intervention.

Math fluency in the third introduction of Phase A decreased almost immediately. After four sessions, Phase $\mathrm{C}$ was re-introduced a last time. Math fluency returned to a relatively high level and was clearly better than performance in Phase A. Similar trends in the data between phases can be seen in Figures 2 and 3.

Figure 2 - Grade Level Group Medians

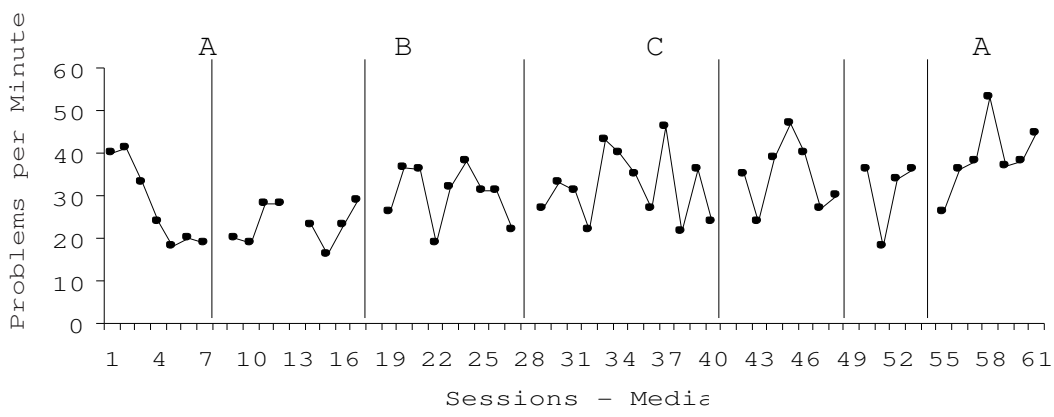


Figure 3 - Below Grade Level Group Medians

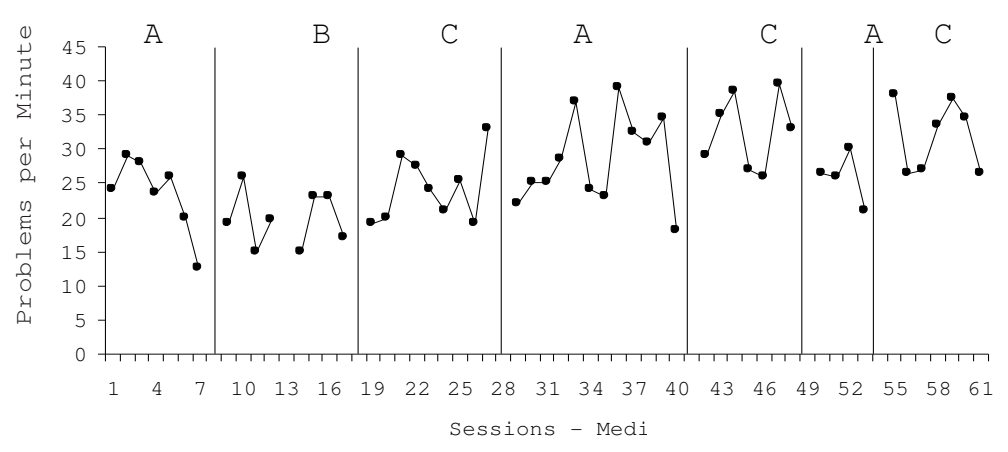

Figures 2 and 3 depict the performances of the two math groups Grade Level and Below Grade Level. Both graphs mirror performance in the class graph; however, the effect of the physical activity appears to be much stronger for the below grade level group than for their grade level peers. The number of problems answered correctly by the below grade level group appeared to be more clearly affected (i.e., higher trend in data path) by the physical activity in Phase $\mathrm{C}$ and in Phase A.

Despite small changes in levels of data paths between phases, it is visible that the physical activity did have some effect. Math fluency of the students on days they did not do any physical activity was drastically different from days when they did. Anecdotal comments from the teacher were interesting and supportive of the physical activity. She reported observing some positive changes in her students' classroom behavior and anxiety levels.

\section{Discussion}

Physical activity does not negatively affect academic performance (Blaydes, 2001; Sallis, et al., 1999). In fact, it can help children to do better. Overall, math fluency improved. However, improvement was not limited to only math fluency. Improvements in the behavior of the whole class after the physical activity were made, and the teacher reported anecdotally that they were able to get more done. She could accomplish her list of the day's activities with some time left for the children to do their homework. However, on days when there was no physical activity, she was not often able to accomplish as much. More time was spent getting the class to settle down and maintain their attention, and 
often the students were not left with any time to even start their homework because they either barely finished their day's activities or did not finish them.

The teacher also reported that the children enjoyed both activities immensely. They often chose not to drink water after the physical activity so they could get started on the math activity. It is very exciting to hear that an entire class of second grade children was very motivated to do a short physical activity. The effect of the physical activity on math fluency and behavior confirmed this teacher's belief that outdoor activity of a physically demanding nature is an important part of every child's day. The children were also so excited to get started on the math activity that the time it took to return to the classroom was minimal. With the math activity taking one minute to complete, it did not take much longer for the teacher to correct. In the whole scheme of things, both activities did not take much time at all. Classroom teachers have many responsibilities; however, improved student behavior after physical activity can make up for any time used outside of class in the amount of work that may be accomplished. These findings are supported by Sallis et al (1999), who reported that physical activity had no negative effect on academic achievement. There is much more to cover relative to academics, but physical activity should not take a back seat to other subject areas when in fact it can enhance performance in those areas (Summerford, 2001).

\section{References}

Binder, C., Haughton, E., \& Van Eyk, D., (1990). Increasing endurance by building fluency: Precision teaching attention span. Teaching Exceptional Children, 22(3), 24-27.

Blaydes, J. (2001). Advocacy: A case for daily quality physical education. Teaching Elementary Physical Education, 12(3), 9-12.

Cooper, J. O., Heron, T. E., \& Heward, W. L. (1987). Applied behavior analysis. New York: Macmillan.

Corbin, C. B, \& Pangrazi R.P. (1998). Physical activity for children. A statement of guidelines. Reston, VA: Council on Physical Education for Children (COPEC) of the National Association for Sport and Physical Education.

Hannaford, C. (1995). Smart moves. Why learning is not all in your head. Arlington, VA: Great Ocean Publishers.

Jensen, E. (1998). Introduction to brain-compatible learning. San Diego, CA: The Brain Store.

Jensen, E. (2000). Brain-based learning. San Diego, CA: The Brain Store. 
National Association for Sport and Physical Education (NASPE). (1995).

Moving into the future: National standards for physical education. St. Louis, MO: Mosby.

Sallis, J. F., McKenzie, T. L., Kolody, B., Lewis, M., Marshall, S., \& Rosengard, P. (1999). Effects of health-related physical education on academic achievement: Project spark. Research Quarterly for Exercise and Sport, 70, 127-134.

Summerford, C. (2001). What is the impact of exercise on brain function for academic learning? Teaching Elementary Physical Education, 12(3), 6-8.

United States Department of Health and Human Services (DHHS). (2001). Physical activity and good nutrition: Essential elements to prevent chronic diseases and obesity (at a glance). Retrieved October 30, 2001, from: http://www.cdc.gov/nccdphp/dnpa/dnpaaag.htm

Werner, P., Timms, S., \& Almond, L. (1996). Health stops: Practical ideas for health-related exercise in preschool and primary classrooms. Young Children, 51(6), 48-55. 